University of Nebraska - Lincoln

DigitalCommons@University of Nebraska - Lincoln

U.S. Environmental Protection Agency Papers

U.S. Environmental Protection Agency

2010

\title{
Assessing the effects of exposure timing on biomarker expression using $\boldsymbol{\beta}$-estradiol
}

K. M. Hyndman

Saint Cloud State University

A. Biales

U.S. Environmental Protection Agency

S. E. Bartell

Saint Cloud State University

H. L. Schoenfuss

Saint Cloud State University, hschoenfuss@stcloudstate.edu

Follow this and additional works at: https://digitalcommons.unl.edu/usepapapers

Hyndman, K. M.; Biales, A.; Bartell, S. E.; and Schoenfuss, H. L., "Assessing the effects of exposure timing on biomarker expression using $\beta$-estradiol" (2010). U.S. Environmental Protection Agency Papers. 102.

https://digitalcommons.unl.edu/usepapapers/102

This Article is brought to you for free and open access by the U.S. Environmental Protection Agency at DigitalCommons@University of Nebraska - Lincoln. It has been accepted for inclusion in U.S. Environmental Protection Agency Papers by an authorized administrator of DigitalCommons@University of Nebraska - Lincoln. 


\title{
Assessing the effects of exposure timing on biomarker expression using $17 \beta$-estradiol
}

\author{
K.M. Hyndman ${ }^{\text {a }}$, A. Biales ${ }^{\text {b }}$, S.E. Bartell ${ }^{\text {a }}$, H.L. Schoenfuss ${ }^{\text {a,* }}$ \\ a Aquatic Toxicology Laboratory, Saint Cloud State University, WSB-273, 720 Fourth Avenue South, St. Cloud, MN 56301, United States \\ ${ }^{\mathrm{b}}$ U.S. Environmental Protection Agency, Cincinnati, OH 45268, United States
}

\section{A R T I C L E I N F O}

\section{Article history:}

Received 26 September 2009

Received in revised form 31 October 2009

Accepted 5 November 2009

\section{Keywords:}

$17 \beta$-Estradiol (E2)

Vitellogenin

mRNA

Histopathology

Behavior

Fathead minnow

\begin{abstract}
A B S T R A C T
Temporal and spatial variability in estrogenicity has been documented for many treated wastewater effluents with the consequences of this variability on the expression of biomarkers of endocrine disruption being largely unknown. Laboratory exposure studies usually utilize constant exposure concentrations which may produce biological effects that differ from those observed in organisms exposed in natural environments. In this study, we investigated the effects of differential timing of exposures with $17 \beta-$ estradiol (E2) on a range of fathead minnow biomarkers to simulate diverse environmentally relevant exposure profiles. Two 21-day, replicate experiments were performed exposing mature male fathead minnows to $\mathrm{E} 2$ at time-weighted mean concentrations (similar average exposure to the contaminant during the 21-day exposure period; $17 \mathrm{ng}$ E2/L experiment 1; $12 \mathrm{ng}$ E2/L experiment 2) comparable to E2 equivalency values (EEQ) reported for several anthropogenically altered environments. A comparable time-weighted mean concentration of E2 was applied to five treatments which varied in the daily application schema: E2 was either applied at a steady rate (ST), in a gradual decreasing concentration (HI), a gradual increasing concentration (LO), applied intermittently (IN), or at a randomly varying concentration (VA). We assessed a range of widely used physiological (vitellogenin mRNA induction and plasma concentrations), anatomical (body and organ indices, secondary sex characteristics, and histopathology), and behavioral (nest holding) biomarkers reported to change following exposure to endocrine active compounds (EACs). All treatments responded with a rise in plasma vitellogenin concentration when compared with the ethanol carrier control. Predicatively, vitellogenin mRNA induction, which tracked closely with plasma vitellogenin concentrations in most treatments was not elevated in the HI treatment, presumably due to the lack of E2 exposure immediately prior to analysis. The ability of treatment male fish to hold nest sites in direct competition with control males was sensitive to E2 exposure and did yield statistically significant differences between treatments and carrier control. Other biological endpoints assessed in this study (organosomatic indices, secondary sex characteristics) varied little between treatments and controls. This study indicates that a broad suite of endpoints is necessary to fully assess the biological consequences of fish exposure to estrogens and that for at least field studies, a combination of vitellogenin mRNA and plasma vitellogenin analysis are most promising in deciphering exposure histories of wild-caught and caged fishes.
\end{abstract}

(c) 2009 Elsevier B.V. All rights reserved.

\section{Introduction}

Endocrine active compounds (EACs) in aquatic environments have been a growing concern due to evidence indicating disruption of normal reproductive function in male fish. Studies have shown increased vitellogenin production (Hemmer et al., 2002), impaired testicular growth (Jobling et al., 2002), disrupted gonadal morphology (Purdom et al., 1994; Harries et al., 1997; Jobling et al., 1998), and impaired reproductive behavior (Bayley et al., 1999;

\footnotetext{
* Corresponding author. Tel.: +1 320308 3130; fax: +1 3203084166.

E-mail address: hschoenfuss@stcloudstate.edu (H.L. Schoenfuss).
}

Bjerselius et al., 2001; Schoenfuss et al., 2002) in fishes exposed to EACs.

In most laboratory based chemical exposure studies, fish are subjected to continuous, steady concentrations of EACs throughout the entire study (Fig. 1a). However, steady exposure conditions may not be entirely realistic for wild fish. Martinovic et al. (2008) measured estrogenic activity of wastewater treatment plant effluent discharge and found daily, even hourly, variations in the range of 10-100 ng 17 $\beta$-estradiol (E2) equivalents/L (EEQs) (Fig. 1b). Several other studies in the US (Hemming et al., 2001; Vajda et al., 2008) and Europe (Rogers-Grey et al., 2000; Ternes et al., 1999) also reported both spatial and temporal variability in the estrogenicity of wastewater effluents. Furthermore, the timing of exposure may 
alter the expression of biomarkers when compared with an exposure to a steady concentration of a compound. Panter et al. (2000) demonstrated that an intermittent exposure to E2 increased effects observed in male fathead minnows when compared to those effects elicited through a steady concentration exposure. Studies on other chemicals have also shown that temporally variable exposures alter effects compared to steady exposures (Diamond et al., 2005; Handy, 1994).

Despite mounting evidence that estrogenicity in many environments exhibits significant temporal and spatial variability, few studies have assessed the potential for differential effects in fish exposed through temporally varying EAC concentrations profiles. One study used a variable exposure profile where the concentration of EACs varied randomly throughout the experiment (Martinovic et al., 2008). Another study employed an intermittent approach where the concentration of EACs was pulsed every few days (Panter et al., 2000). Other plausible exposure profiles have not been investigated through laboratory studies. For example, prolonged precipitation may result in the dilution of EAC concentration in an aquatic environment receiving treated wastewater effluent and effectively diminishes the fishes' exposure to EACs over time (Fig. 1a). Alternatively, a lack of precipitation may result in reduced dilution of treated wastewater effluent in receiving waters and through evaporation results in a gradual increase of EACs in the aquatic ecosystem (Fig. 1b). In this study, an attempt was made to mimic these exposure profiles while keeping the total mass of E2 delivered per treatment the same (similar timeweighted mean concentrations per treatment over the 21-day duration of the study). This approach allowed for an assessment of the overall accumulated response to different exposure profiles.

E2 was used as a model EAC in this study, because the knowledge base on this chemical is extensive and it has been used as a surrogate for many EACs when investigating exposure effects in fish. An approximate, time-weighted mean nominal concentration of $15 \mathrm{ng}$ E2/L was used across treatments because this concentration is known to induce vitellogenin production in fish and it approximates relevant concentrations of the sum of EACs as reported in previous studies (Martinovic et al., 2008; Vajda et al., 2008). Thus, each exposure scenario received the same mass of E2 during the 21-day exposure period with the timing of E2 concentrations varied between treatments.

A range of physiological, anatomical, and behavioral endpoints was assessed in this study as we expected effects to vary between exposure profiles. Vitellogenin production in male fishes, measured through a mRNA induction assay or by quantification of the protein in fish plasma, has become a standard endpoint for acute exposure to estrogenic EACs. Among the anatomical endpoints, changes in secondary sex characteristics, organ indices, and histopathological changes (including intersex) have all been noted in conjunction with EAC exposures in field and/or laboratory studies (Jobling et al., 2002; Purdom et al., 1994; Harries et al., 1997). In previous studies, behavioral endpoints were often found to be sensitive biomarkers of the effects of EACs and several studies have demonstrated impaired reproductive behaviors following exposure to EACs (Bayley et al., 1999; Bjerselius et al., 2001; Schoenfuss et al., 2002).

By combining a range of relevant exposure profiles, using comparable time-weighted mean E2 concentrations that fall within the range of total EEQ concentrations measured in several previous studies, we tested the hypothesis that biological responses in aquatic vertebrates will vary with differing E2 exposure profiles. In addition, we evaluated whether an endpoint matrix that included physiological, anatomical, and behavioral endpoints may be used to decipher exposure histories of wild-caught and caged fishes from field studies.

\section{Materials and methods}

\subsection{Experimental design}

Two comparable exposure experiments were conducted at the St. Cloud State University Aquatic Toxicology Laboratory in St. Cloud, Minnesota. In both experiments groups of male fathead minnows were exposed to comparable time-weighted concentrations of E2 for 21 days. Following the exposures a subset of 20 fish from each treatment were sacrificed and assessed for a range of anatomical and physiological endpoints while the remaining treatment males were paired up with solvent control males for a behavioral assay. The behavioral assay challenged the treatment fish to acquire and defend a nest site in direct competition with a control male fish.

\subsection{Exposure chemicals}

A common stock solution of E2 (Sigma, St. Louis, USA) in 100\% ethanol was prepared at a concentration of $40 \mathrm{mg}$ E2/L. Chemical preparations and additions to the exposure system are described in detail in Barber et al. (2007). Treatment specific daily spikes were drawn from this stock solution, topped to $2 \mathrm{~mL}$ with $100 \%$ ethanol (to assure similar carrier concentrations in all treatments and control), and stored at $4{ }^{\circ} \mathrm{C}$ until use. For all treatments, fresh aqueous exposure solutions were prepared daily by mixing a spike of the appropriate concentrated stock solution in $10 \mathrm{~L}$ of deionized water in an amber glass bottle. Solvent concentrations did not exceed $1.8 \mu \mathrm{L}$ ethanol/L, which is well below solvent concentrations used in previous experiments (Schoenfuss et al., 2002; Bistodeau et al., 2006; Barber et al., 2007). After spike addition, each amber bottle was gently agitated for $10 \mathrm{~s}$, and the neck of the bottle was covered with aluminum foil. A stainless steel tube was used to draw the daily exposure solution into a stainless steel mixing chamber located above the treatment aquaria at a nominal rate of $0.008 \mathrm{~L} / \mathrm{min}$ using a Cole-Palmer Masterflex 7523-40 peristaltic pump (Vernon Hills, IL). In the stainless steel mixing chamber ground water from a dedicated well was added to the continuous flow of the daily exposure solution to achieve the final aquarium concentration of E2. This solution was then gravity fed to the treatment aquaria at a rate of $0.2 \mathrm{~L} / \mathrm{min}$ aquarium. The flow rate resulted in approximately 18 water exchanges each day. Consequently, each aquarium, independent of the treatment, received a total nominal mass of $91 \mu \mathrm{g}$ E2 during the 21-day exposure experiment (16 L aquarium $\times 18$ exchanges per day $\times 21$ days $\times 15 \mathrm{ngE} 2 / \mathrm{L}$ ). It is important to note that the purpose of the experiments was not to assess the effects of E2 per se, but rather to compare the effects of different exposure profiles and to establish whether endpoint matrices could be utilized to decipher the exposure history of fishes, thus rendering absolute E2 concentrations of lesser significance in this study.

\subsection{Exposure organisms}

For both experiments, adult male fathead minnows were obtained from a laboratory fish supplier (Environmental Testing and Consulting, Superior, WI). Fish were maintained following US EPA guidelines (Denny, 1987) throughout the experiments at constant environmental conditions (16:8 h light:dark, $21^{\circ} \mathrm{C}$ water temperature) and fed frozen brine shrimp (Artemia franciscana, San Francisco Bay Brand, Inc., Newark, CA) twice daily ad libitum. Animal use and care in all experiments was approved by the St. Cloud State University Animal Use and Care Committee (IACUC).

In both experiments, mature male fathead minnows were randomly assigned to solvent control or exposure aquaria at 10 fish per $16 \mathrm{~L}$ aquarium. Four aquaria were assigned to each of the five exposure scenarios in the first study (40 fish/treatment) and three aquaria per scenario in the second study (30 fish/treatment). Eight 

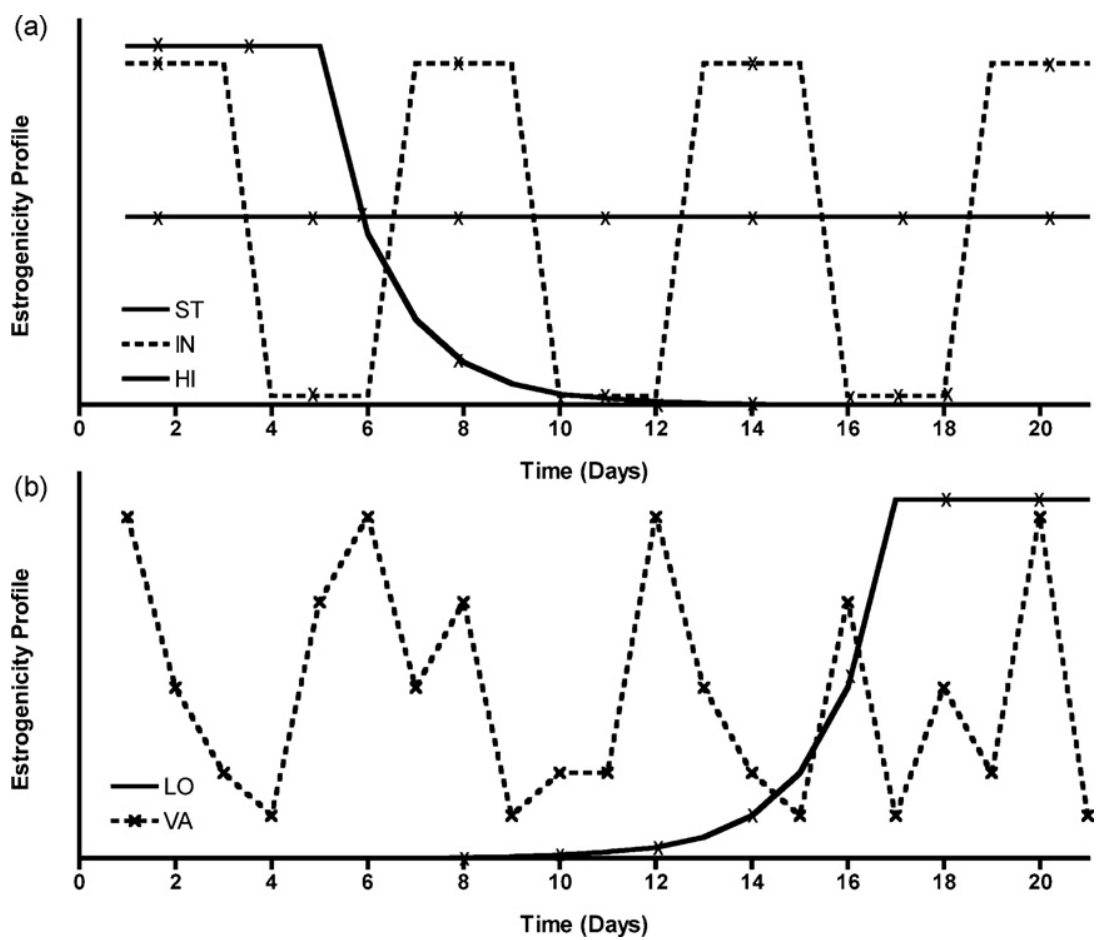

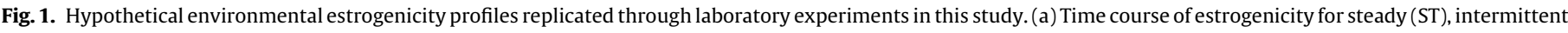

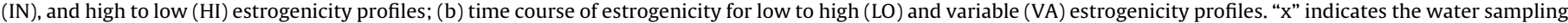
frequency for each treatment.

aquaria were assigned to control fish in both studies to provide males for the competitive spawning assay. Following the 21-day exposure, 20 males in each treatment (five fish randomly netted from each aquarium within a treatment) were sacrificed in MS222 (Argent Chemical Laboratories, Redmond, WA) and assessed for physiological and anatomical endpoints. The remaining E2 exposed males were individually paired with solvent control males, based on similar secondary sexual characteristics, to compete for reproductive opportunities in the behavioral challenge assay (see Section 2.4.3). The five-day behavioral challenge assay, therefore, represents a depuration period for the previously E2 exposed male fish. Following the behavioral challenge assay, these fathead minnows were sacrificed and analyzed for plasma vitellogenin concentrations, organosomatic indices, and secondary sex characteristics to determine whether the depuration period altered any biomarkers when compared to fish in the same treatment analyzed immediately following the 21-day exposure.

\subsection{Analysis}

\subsubsection{Water quality}

Water samples were collected daily (VA), every second day (HI, LO), or every third day (ST, IN) from the outflow of the stainless steel mixing chambers where ground water and the treatment specific E2 concentrations were mixed prior to delivery to the four aquaria of a treatment. E2 concentrations were measured via an antibodycapture ELISA (Kit 582251.1) purchased from Cayman Chemicals (Ann Arbor, MI). Briefly, microtiter plates were coated with mouse anti-rabbit IgG at a constant concentration per well. Samples or standards were mixed with estradiol tracer and estradiol antiserum and incubated in the microtiter wells. The estradiol tracer was a conjugate of estradiol-acetylcholinesterase (AChe) and the antibody was a rabbit polyclonal anti-estradiol antiserum. The resulting antibody-estradiol complexes were bound to the coated mouse anti-rabbit IgG, incubated for $1 \mathrm{~h}$ at room temperature, washed three times and detected by the addition of Ellman's reagent, con- taining a substrate for AChe. Absorbance was read at $405 \mathrm{~nm}$ on a Multiskan EX (Thermo Electron). Standard curves were constructed and sample values calculated using the accompanying Multiskan software. The standards were prepared as a seven step 2.5-fold serial dilution, with a range of $640-2.6 \mathrm{pg} / \mathrm{mL}$. The standard curves were accepted with $r$-squared values of $>0.99$. The samples were prepared undiluted, and upper and lower limits of detection were 640 and $2.6 \mathrm{pg} / \mathrm{mL}$, respectively.

As it was not feasible to sample each treatment every day in both replicates of the experiment (over 250 total samples), the following sampling schema was applied: the HI and LO treatments were measured every second day during the 16 days these treatments received $\mathrm{E} 2$ (and one more time thereafter to assure that no $\mathrm{E} 2$ was left in the exposure system). Water samples from the ST and IN treatments were collected every third day. The VA treatment was measured daily and needed no adjustment.

\subsubsection{Biological endpoints}

2.4.2.1. Plasma vitellogenin analysis. After fish were deeply anaesthetized in $0.1 \%$ MS-222, fish tails were severed to harvest blood using a heparinized micro hematocrit tube. Blood was immediately centrifuged to isolate plasma ( $3400 \mathrm{rpm}$ for $5 \mathrm{~min}$ ), and the plasma was placed on ice and transferred to a $-80^{\circ} \mathrm{C}$ freezer until analysis. Plasma vitellogenin levels were measured via a competitive antibody-capture ELISA. Microtiter wells were coated with fathead minnow vitellogenin at an approximate concentration of $4 \mu \mathrm{g} / \mathrm{mL}$ in coating buffer $(0.35 \mathrm{M}$ sodium bicarbonate, $0.15 \mathrm{M}$ sodium carbonate, $\mathrm{pH}$ 9.6). A pre-incubation binding step was carried out where plasma samples or standards were diluted and mixed 1:1 (1:20,000 final dilution) with a polyclonal anti-fathead minnow vitellogenin antibody (provided by Gerald LeBlanc, NC State University) and incubated at $37^{\circ} \mathrm{C}$ for $2 \mathrm{~h}$. Just prior to the completion of the pre-incubation, plates were washed three times with wash buffer in an automated plate washer and $200 \mu \mathrm{L}$ of each sample or standard was added. After a $1 \mathrm{~h}$ incubation at room temperature, plates were again washed and $200 \mu \mathrm{L}$ of horseradish peroxidase 
labeled anti-rabbit IgG secondary antibody was added and incubated for $1 \mathrm{~h}$ at room temperature. After washing plates, $200 \mu \mathrm{L}$ of TMB substrate (Sigma, St. Louis, USA) was added and the plates were incubated in the dark for $15 \mathrm{~min}$. Absorbance was read at $620 \mathrm{~nm}$ on a Multiskan EX (Thermo Electron). Standard curves were constructed and sample values calculated using the accompanying Multiskan software. The standards were prepared as a seven step two-fold serial dilution with a range of $4.8-0.075 \mathrm{ug} / \mathrm{mL}$. The standard curves produced were robust, with $r$-squared values routinely higher than 0.99 . Periodically the lowest standard $(0.075 \mathrm{ug} / \mathrm{mL})$ was removed from the curve to keep the $r$-squared above 0.99 . The upper and lower limits of detection for the assay were $5 \mathrm{mg} / \mathrm{mL}$ and $3.75 \mathrm{ug} / \mathrm{mL}$, respectively. Each plate contained an internal standard control of vitellogenin at three dilutions within the standard curve range as well.

2.4.2.2. Vitellogenin $m R N A$ analysis. RNA was isolated from frozen liver tissue following the TriReagent protocol (MRC, Cincinnati, $\mathrm{OH}$ ). Reverse transcription reactions were done using $250 \mathrm{mg}$ of total RNA according to Biales et al. (2007). Following reverse transcription, cDNA was diluted 1:5 with DEPC water (Ambion, Austin, TX). QPCR reactions were constructed with $2 \mathrm{~mL}$ diluted cDNA, 1X Fast Sybr green PCR Master Mix (AB Inc, Foster City, CA) and $0.5 \mathrm{mM}$ each of either vitellogenin or $18 \mathrm{~S}$ (Ambion) gene specific primers each in a $20 \mathrm{~mL}$ total reaction volume. All samples were done in at least duplicate. QPCR cycling parameters were as follows: $95^{\circ} \mathrm{C}$ for $20 \mathrm{~s}$; followed by 40 cycles of $95^{\circ} \mathrm{C}$ for $1 \mathrm{~s}, 60^{\circ} \mathrm{C}$ for $20 \mathrm{~s}$, followed by a fluorescent data acquisition. After amplification, a meltingcurve analysis ranging from 60 to $95^{\circ} \mathrm{C}$ was completed for each reaction to confirm the amplification of a single product of the correct melting temperature. To aid in inter-plate comparison a vitellogenin or $18 \mathrm{~S}$ standard was run in at least duplicate on each reaction plate. $\mathrm{Ct}$ values were averaged among technical replicates and data were quantified using the equation proposed by Pfaffl et al. (2002). All data were normalized to $18 \mathrm{~S}$ expression and calibrated to the standard on each reaction plate.

2.4.2.3. Organosomatic index. Whole body weights were measured for each male fish at the time of analysis $(0.01 \mathrm{~g}$ precision, Acculab Vicon, Edgewood, NY). Body weight and total length was used to calculate the body condition index $(\mathrm{BCI}=$ body weight/total length $\left.{ }^{3}\right)$.Gonads and livers from each male were excised and immediately weighed $(0.001 \mathrm{~g}$ precision, Mettler Toledo AG245, Columbus, $\mathrm{OH}$ ). Liver and whole body weights were used to calculate the hepatosomatic index (HSI = liver weight/whole body weight). Gonad and whole body weights were used to calculate the gonadosomatic index (GSI = gonad weight/whole body weight).

2.4.2.4. Secondary sex characteristics. Prior to organ excision, secondary sex characteristics were evaluated. This evaluation used a simple, blind scoring system modified after Smith (1978). The prominence of the tubercles was scored on a scale of $0-3$ with 0 indicating no expression and 3 prominent expression of the secondary sex characteristic. The dorsal pad and color/banding intensity was evaluated by a similar method and scored on a scale of $0-3$. For statistical analysis, the sum of all three secondary sex characteristics was calculated and compared between treatments.

2.4.2.5. Histopathology. Following removal, gonads were fixed in $10 \%$ neutral buffered formalin for $24 \mathrm{~h}$ (Gabe, 1976). After fixation, tissues were dehydrated in a series of ethanol and xylene baths before being embedded in paraffin. Embedded tissues were sectioned at approximately $1 / 3$ and $2 / 3$ of the length of the testis using a Reichert-Jung cassette microtome (4-6 $\mu \mathrm{m}$ sections). Sectioned tissues were stained using a standard Haematoxylin and Eosin counter stain protocol modified after Gabe (1976) and Carson
(1997). Histological slides were scored on a 0 (absent) to 4 (abundant) scale for the presence of spermatozoa (mature sperm), spermatogonia (developing sperm) and liver hepatocyte vacuolization. To assess the overall stage of spermatogenesis in the testis of the fathead minnows, a ratio of spermatozoa:spermatogonia abundance was calculated and used for the statistical comparison of treatments.

\subsubsection{Behavioral challenge assay}

Once the 21-day exposure period was completed, a subsample of 20 fish per treatment was sacrificed for assessment of physiological and anatomical endpoints. The remaining E2 exposed male fathead minnows were paired with solvent control males based on similar secondary sex characteristics for the behavioral challenge assay (Bistodeau et al., 2006; Barber et al., 2007; Martinovic et al., 2007). Exposed and control males received small caudal fin clips (a corner of either the superior or inferior portion of the caudal fin was removed) so that the observer could distinguish fish from the two treatments. Fin clips were assigned based on the flip of a coin to create "blind observations", whereas the observer was unaware of the exposure history of the males. In addition, alternating fin clips avoided bias between control and exposed males as both groups received comparable numbers of upper and lower fin clips. One treated male and one control male of comparable size and secondary sex characteristics (judged only visually, as it was important for the experimental integrity to avoid extended periods of stress for the fish) were then simultaneously placed into a 7-L aquarium. Based on the number of available treatment and control fish, nine to 16 competitive spawning assays were setup for each treatment (an insufficient number of control males prevented the assessment of the VA treatment in experiment 1). Each spawning aquarium contained one nest site, made of a short section of $8 \mathrm{~cm}$ diameter PVC pipe cut in half. Twice daily (between 8 and 10 a.m. and 2 and 4 p.m.), for the following five days, the nest holding male was identified by its respective fin clip. The times of observation coincide with the highest reproductive activity (usually in the morning) and after most reproductive activity for the day was completed (afternoon). A successful male was defined as one that exhibited aggressive behavior towards other fish in the aquarium, while clearly protecting the nest site. This behavior typically includes butting using the newly formed tubercles, and chasing other fish away from the nest site (Unger, 1983).

\subsection{Statistical analysis}

The assumption of normality for all data sets was tested with the Kolmogorov-Smirnov test for normality prior to any additional analysis (Prism 4.01 statistical package, GraphPad Software Inc., Oxnard, CA). As the majority of data were found not to meet standards of homogeneity, data were analyzed using a Kruskal-Wallis analysis followed by a Dunn's post-test. For data sets with subsequent sampling (after exposure and following the five-day behavioral assay), changes in individual treatments were assessed using a Mann-Whitney $U$-test. Vitellogenin mRNA data were log2 transformed and analyzed using a one-way ANOVA followed by Bonferroni post-test. Nest holding abilities of the exposed and control males in the competitive spawning assays were assessed using a Fisher's Exact Test (contingency table). A probability of $p<0.05$ was set as level of significance for all comparisons.

\section{Results}

\subsection{Survival rates and aqueous $17 \beta$ estradiol concentrations}

Survival rates of greater than $\geq 95 \%$ were observed during both experiments in all treatments (lowest survival rate 
Table 1

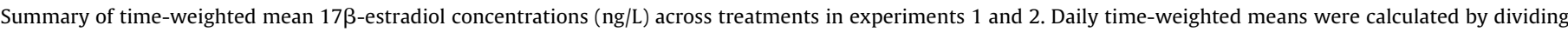
the daily exposure concentrations by the 21-day duration of the study.

\begin{tabular}{|c|c|c|c|c|c|}
\hline & & \multirow[t]{2}{*}{$n^{\mathrm{a}}$} & \multirow{2}{*}{$\begin{array}{l}\text { Daily time-weighted, } \\
\text { mean } \pm \text { standard error }^{\mathrm{b}}\end{array}$} & \multicolumn{2}{|l|}{ Range of concentrations } \\
\hline & & & & Maximum concentration (sample day) & Minimum concentration (sample day) \\
\hline \multicolumn{6}{|l|}{ Experiment 1} \\
\hline Steady & ST & 7 & $17 \pm 1.4$ & 26 (day 7) & 9 (day 16$)$ \\
\hline Intermittent & IN & 7 & $15 \pm 2.4$ & 28 (day 1 ) & $<\mathrm{DL}^{\mathrm{C}}$ (days 10,16 ) \\
\hline High $\rightarrow$ low & $\mathrm{HI}$ & 7 & $7.8 \pm 2.5$ & 35 (day 1 ) & $<$ DL (day 11$)$ \\
\hline Low $\rightarrow$ high & LO & 8 & $6.5 \pm 1.5$ & 11 (day 17 ) & $<$ DL (day 5) \\
\hline Variable & VA & 20 & $12 \pm 1.9$ & 34 (day 20) & 1 (days 7,15 ) \\
\hline \multicolumn{6}{|l|}{ Experiment 2} \\
\hline Steady & ST & 7 & $12 \pm 0.9$ & 18 (day 1 ) & 6 (day 10 ) \\
\hline Intermittent & IN & 7 & $16 \pm 2.7$ & 30 (day 1 ) & $<$ DL (days 7,10 ) \\
\hline High $\rightarrow$ low & $\mathrm{HI}$ & 7 & $5.9 \pm 1.9$ & 19 (days 1,5 ) & $<\mathrm{DL}$ (days 11,13 ) \\
\hline Low $\rightarrow$ high & LO & 8 & $7.8 \pm 2.2$ & 27 (day 17 ) & $<\mathrm{DL}($ day 5,9$)$ \\
\hline Variable & VA & 19 & $11 \pm 1.8$ & 30 (day 1$)$ & $<$ DL (day 8) \\
\hline
\end{tabular}

a Sample number $(n)$ indicates the actual number of water samples that were taken and analyzed for each treatment.

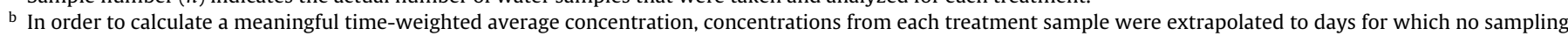
occurred. Variable treatment was sampled daily.

c Detection limit (DL) for $17 \beta$ E2 $=1 \mathrm{ng} / \mathrm{L}$.

in a treatment was 95\% for EtOH in experiment 1). Environmental conditions were stable throughout the experiments (experiment 1: temperature $=21.8 \pm 0.5 ; \mathrm{pH} 7.7 \pm 0.2$; dissolved oxygen: $5.6 \pm 0.2 \mathrm{mg} / \mathrm{L}$; hardness as $\mathrm{CaCO}_{3}=19 \pm 1.4 \mathrm{mg} / \mathrm{L}$; conductivity $=0.92 \pm 0.01 \mathrm{mS} / \mathrm{cm}^{3}$; experiment 2 : temperature $20.6 \pm 0.7^{\circ} \mathrm{C} ; \mathrm{pH} 7.8 \pm 0.1$; dissolved oxygen $=6.2 \pm 0.2$; hardness as $\quad \mathrm{CaCO}_{3}=21 \pm 2.4 \mathrm{mg} / \mathrm{L} ; \quad$ conductivity $=0.86 \pm 0.01 \mathrm{mS} / \mathrm{cm}^{3}$ ). These conditions are reflective of rearing conditions described by Denny (1987) and environmental conditions for fathead minnows during the reproductive season. Concentrations and time-weighted means (Table 1) varied somewhat between treatments and experiments, however, the overall goal of establishing diverse exposure profiles was accomplished. Mean time-weighted mean concentrations across all five treatments was $17 \mathrm{ng} \mathrm{E} 2 / \mathrm{L}$ in experiment 1 and $12 \mathrm{ng}$ E2/L in experiment 2. E2 was detected once in the solvent control in both experiments, likely through aerial transport, but did not elicit a measurable biological response in either experiment.

\subsection{Physiological endpoints}

After the 21-day exposure, vitellogenin mRNA (Fig. 2a and b) expression was consistent for each treatment between experiments with the exception of LO (E2 concentrations rising through the course of the exposure), which was significantly greater in the second experiment when compared with the first $(p<0.01$, Mann-Whitney $U$-test). The IN (intermittent), VA (variable), and LO treatments all had significantly increased vitellogenin mRNA induction compared to ETOH and HI (E2 concentrations slowly decreasing through the course of the experiment) groups $(p<0.01$, Kruskal-Wallis with Dunn's post-test). Male fathead minnows in the solvent control (EtOH) and $\mathrm{HI}$ treatment had no mRNA induction and were statistically different from all other treatments $(p \leq 0.001$, Kruskal-Wallis with Dunn's posttest).

In both experiments, plasma vitellogenin concentrations (Fig. 3a and b) were significantly increased for all treatments com-
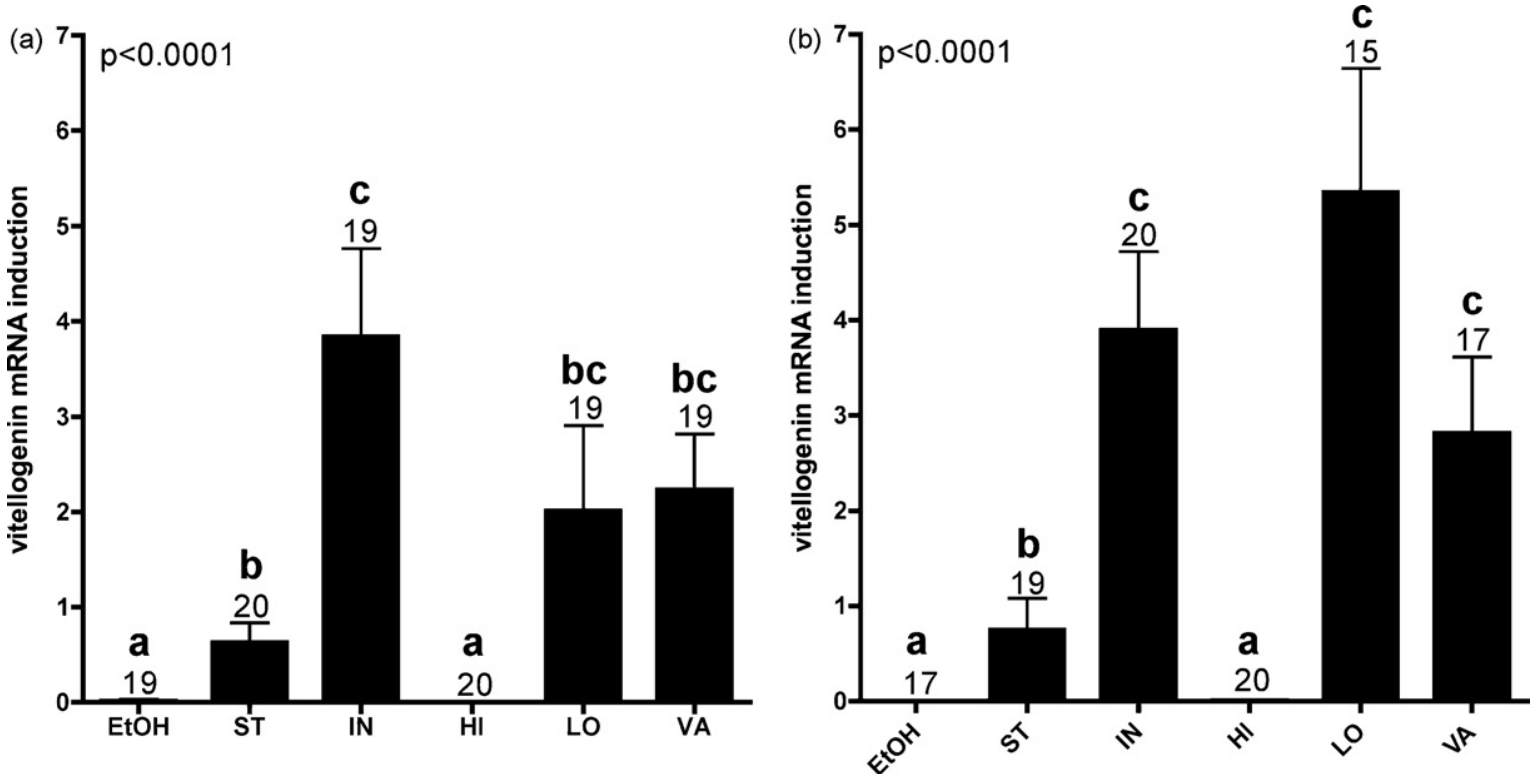

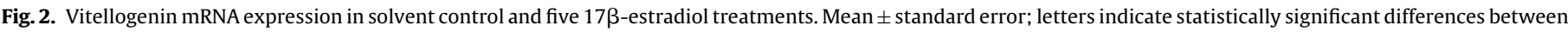

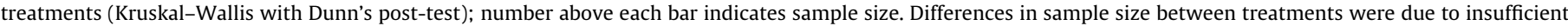
amount of tissue for processing from some fish. See Table 1 for abbreviations. (a) Experiment 1 and (b) experiment 2. 

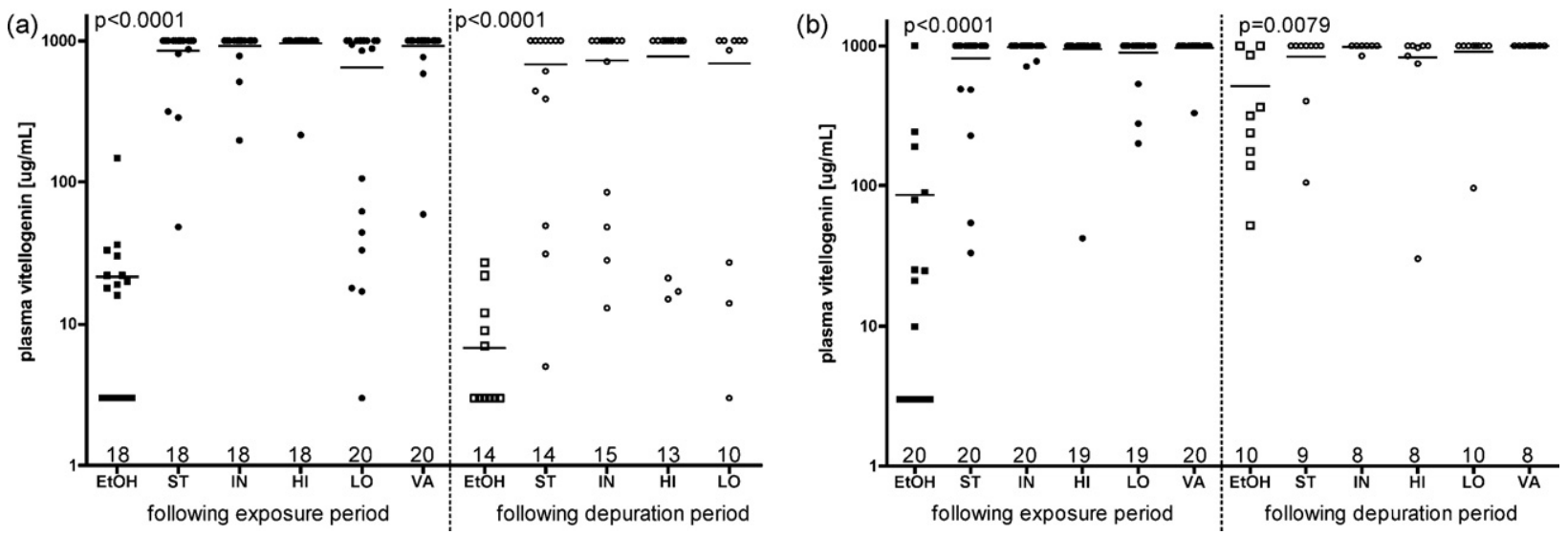

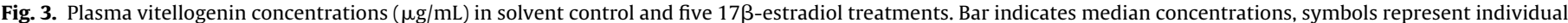

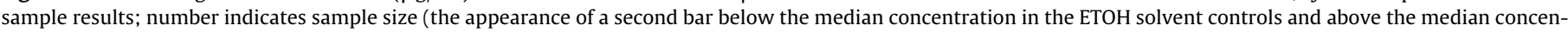

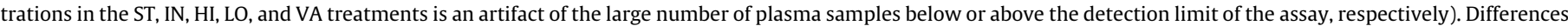
in sample size between treatments were due to insufficient plasma recovery for processing. See Table 1 for abbreviations. (a) Experiment 1 and (b) experiment 2.

pared to the ETOH solvent control ( $p<0.001$, Kruskal-Wallis with Dunn's post-test). Plasma vitellogenin concentrations remained unchanged within E2 exposed fish ( $p>0.05$, Mann-Whitney $U$-test) even following the five-day depuration period of the behavioral challenge assay.

\subsection{Anatomical endpoints}

Body condition index and the organosomatic indices (hepatosomatic index, gonadosomatic index) did not differ between treatments and experiments (data not shown). The sum of secondary sex characteristics (nuptial tubercles, dorsal pad, banding coloration) varied between treatments and experiments (Fig. $4 \mathrm{a}$ and b; black bars) and was generally more pronounced, albeit not to the level of statistical significance $(p>0.05$, Mann-Whitney $U$-test), after the competitive spawning assay (white bars) in experiment 2 (Fig. 4b). Testis histology did not reveal any statistically significant differences in spermatogenesis stage between treatments ( $p>0.05$, Kruskal-Wallis, data not shown). No widespread histopathological changes or ovarian tissues were observed in male fathead minnows in any treatment or experiment. Similarly, the extent of hepatocyte cytoplasmic vacuolization did not vary among treatments or experiments $(p>0.05$, Kruskal-Wallis, data not shown).

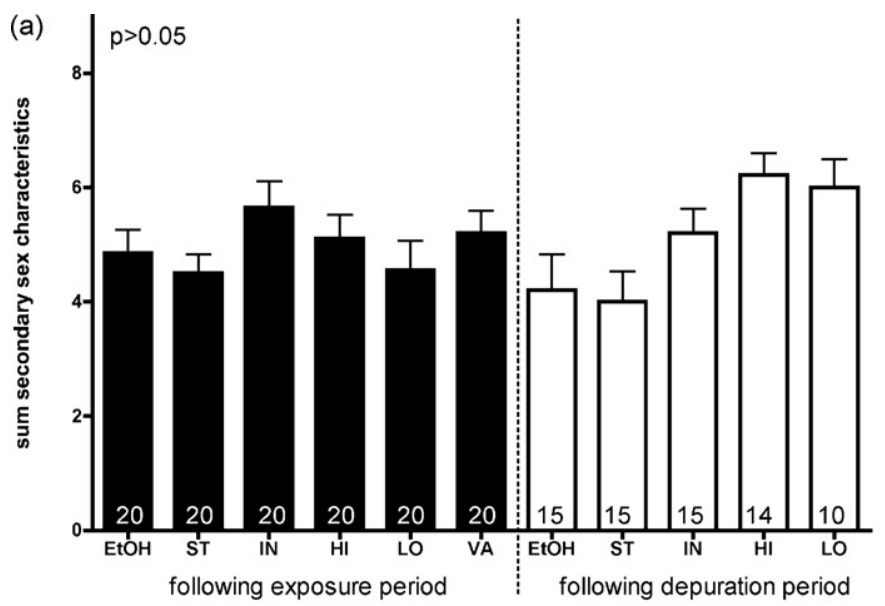

\subsection{Behavioral challenge assay}

The ability of E2 exposed male fathead minnows to directly compete in a paired behavioral challenge assay varied between treatments and experiments (Fig. 5a and b). In the first experiment, male fathead minnows from the ST treatment were significantly $(p<0.001$, Fisher's Exact Test) out-competed by control males for access to nest sites, with control males holding about $65 \%$ of all nest sites in both experiments. In contrast, in the second experiment (Fig. 5b), ST treatment males were more successful than their solvent control competitors to hold and defend a nest site while HI treatment male fathead minnows were significantly $(p \leq 0.01)$ out-competed by control males, which held $65 \%$ of the nest sites.

\section{Discussion}

Two experiments were conducted to investigate how the timing of E2 exposures (Fig. 1a and b) affect the expression of commonly used physiological, anatomical, and behavioral biomarkers of EAC exposure in fish. Although some differences in time-weighted mean concentrations were found between treatments and between experiments, the biological responses observed were largely conserved across the two experiments and the observed patterns of biomarker expression was consistent with the available published

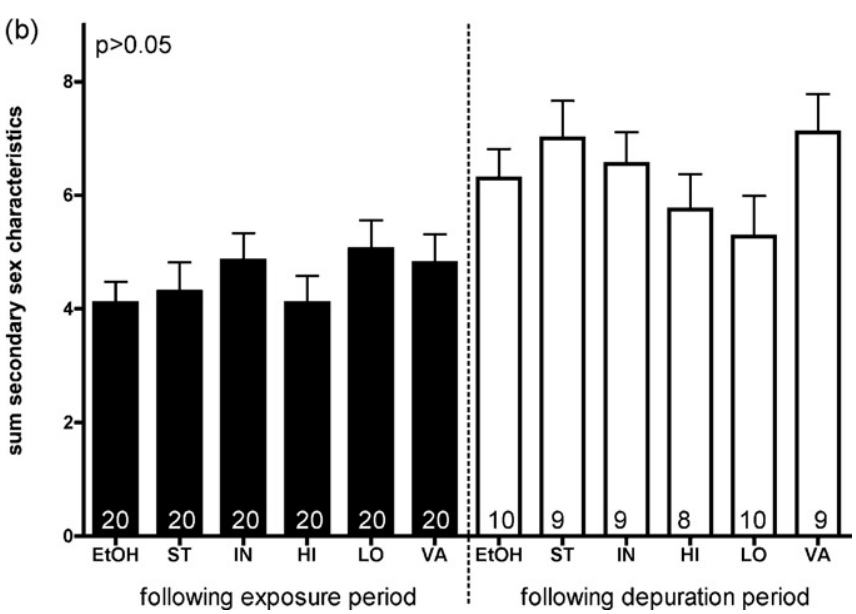

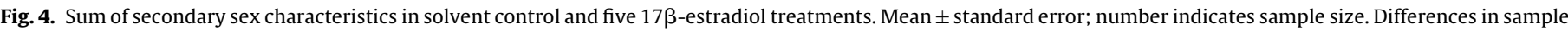

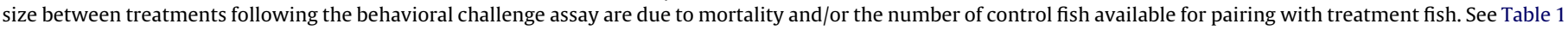
for abbreviations. (a) Experiment 1 and (b) experiment 2. 

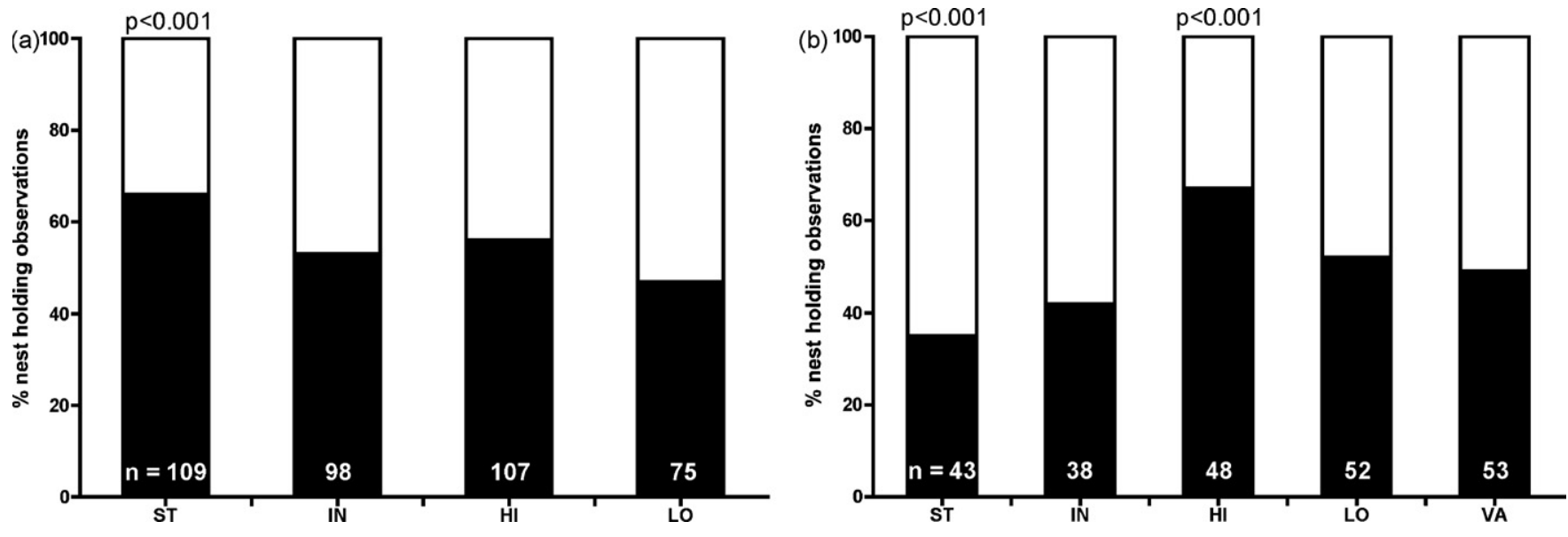

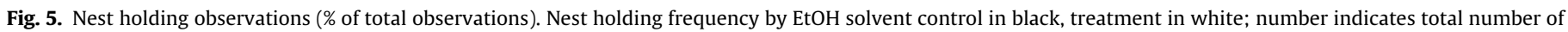

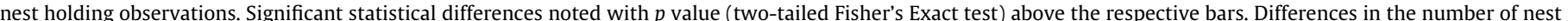

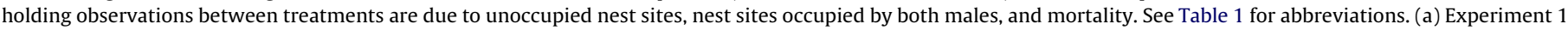
and (b) experiment 2.

literature. As expected, we found significantly increased plasma vitellogenin concentrations for all treatments compared to the solvent control in both experiments. Measurable concentrations of plasma vitellogenin after a 21-day exposure to E2 have been reported in numerous studies and at steady concentrations as low as $25 \mathrm{ng} / \mathrm{L}$ (Liao et al., 2008). However, vitellogenin concentrations did not differ statistically between treatment groups regardless of the timing of the exposure suggesting that the time-weighted mean E2 concentration of as little as $5.9 \mathrm{ng} / \mathrm{L}$ (HI, experiment 2) may be sufficient to result in a ceiling effect as has been reported in other studies (Thorpe et al., 2007; Schmid et al., 2002; Panter et al., 2000; Korte et al., 2000). These and other studies also indicate that once a ceiling plasma vitellogenin concentration has been attained, concentrations remain near the maximum for prolonged depuration periods. Hemmer et al.(2002) reported a roughly 14 day $t^{1} 1 / 2$ clearance rate of plasma vitellogenin in male sheepshead minnows after E2 exposure, which did not differ for two treatments despite an almost 10-fold difference in E2 exposure concentrations (89 and $710 \mathrm{ng} / \mathrm{L}$ ). The consistent clearance rate calculated in that study (Hemmer et al., 2002), when applied to the current investigation with much lower E2 exposure concentrations (5.9-17 ng/L time-weighted mean concentrations), would suggest that even for fish in the HI treatment, where exposure stopped seven days prior to analysis, plasma vitellogenin concentrations would remain significantly elevated for weeks thereafter. This extrapolation is supported by the analysis of E2 exposed fathead minnows following the five-day behavioral challenge assay (amounting to a depuration period) with all treatments still exhibiting plasma vitellogenin concentrations comparable to fish in the same treatment analyzed immediately following the exposures.

Results for vitellogenin mRNA expression were similar for the two experiments. The ETOH solvent control and HI treatments for both experiments had no measurable vitellogenin mRNA expression. The ST treatment had moderate induction of vitellogenin mRNA while the IN, VA, and LO treatment groups had multifold higher mean vitellogenin mRNA expression than even the ST treatment. This pattern of vitellogenin mRNA induction appears to track tightly with the timing of E2 exposure during the two experiments. Treatments with the greatest E2 exposure in the days just prior to the end of each experiment experienced the greatest vitellogenin mRNA induction, while the steady, but lower daily concentration ST treatment resulted in a significantly lower vitellogenin expression. Of particular interest is a comparison of the LO treatments between experiment 1 and 2 with vitellogenin mRNA expression being lower in the first experiment, which also achieved lower maximum E2 concentrations when compared to the second experiment (Table 1). These differences in the same treatment between the two experiments suggests that maximum vitellogenin mRNA induction was not reached by the end of the experiment, in contrast to the observations for the plasma vitellogenin data. For treatments not exposed to $\mathrm{E} 2(\mathrm{EtOH})$, or not for the last 7 days of the exposure $(\mathrm{HI})$, no vitellogenin mRNA expression was measured, suggesting that any previous activity had ceased. These findings are consistent with a previous laboratory exposure study with $17 \alpha$-ethinylestradiol where vitellogenin mRNA expression began to decrease three days into a depuration period and attained control levels after 7 days of depuration (Schmid et al., 2002). Korte et al. (2000) documented maximum vitellogenin mRNA expression within $48 \mathrm{~h}$ of intraperitoneal injections of E2 in male fathead minnows and returned to baseline levels after 6 days. Hemmer et al. (2002) also assessed vitellogenin mRNA expression during the depuration period following a 15-day exposure to 89 and 710 ng E2/L and found rapid reduction in vitellogenin mRNA expression within days of exposure cessation. Gordon et al. (2006) induced near maximum vitellogenin mRNA expression within $24 \mathrm{~h}$ of aqueous addition of a nominal dose of $20 \mathrm{ng} / \mathrm{L}$ ethynylestradiol. In contrast to the HI treatment in the study presented in this manuscript, Gordon et al. (2006) documented elevated vitellogenin mRNA expression even 20 days after the dosing with ethynylestradiol occurred. It is noteworthy that the ST treatment in both experiments resulted in lower mean vitellogenin mRNA induction, even though this treatment had the highest (experiment 1 ) or second highest (experiment 2) timeweighted mean E2 exposure of all treatments. In contrast to the plasma vitellogenin concentrations, no ceiling effect was observed for vitellogenin mRNA expression. This characteristic of the vitellogenin mRNA assay suggests its usefulness not only as an indicator of acute exposure to E2, but also as a potential tool to determine the relative degree of estrogenic exposure in either wild or caged fish. Furthermore, the combination of plasma vitellogenin and vitellogenin mRNA assays may provide some resolution to the recent exposure history of wild fish (Table 2).

In contrast to the unequivocal physiological response in all E2 exposure treatments, anatomical endpoints were less sensitive to the low ng/L exposures to E2 independent of the timing of exposure. The body condition index did not vary between treatments, suggesting that the two exposures did not result in any metabolic impairment. The hepatosomatic index, which is a measure of the relative size of the liver, the main detoxifying organ of the body, also 
Table 2

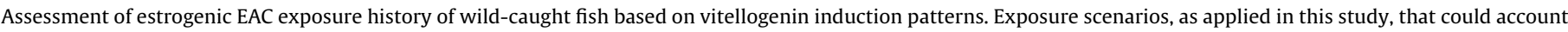
for a pattern of vitellogenin presence and are listed in parenthesis.

\begin{tabular}{|c|c|c|}
\hline \multirow[t]{2}{*}{ Vitellogenin mRNA } & \multicolumn{2}{|l|}{ Plasma vitellogenin } \\
\hline & Low & High \\
\hline Low & $\begin{array}{l}\text { No recent exposure to estrogenic EACs (EtOH } \\
\text { solvent control) }\end{array}$ & $\begin{array}{l}\text { Recent, but not acute estrogenic EAC exposure (HI treatment; potentially } \\
\text { VA and IN treatments) }\end{array}$ \\
\hline High & $\begin{array}{l}\text { Acute, short-term estrogenic EAC exposure (LO } \\
\text { treatment; potentially VA, IN, and ST } \\
\text { treatments) }\end{array}$ & Sustained estrogenic EAC exposure (possible for all treatments except HI) \\
\hline
\end{tabular}

varied little among treatments and control. This result is consistent with the histopathological analysis of the liver which did not reveal any significant alteration in hepatocyte vacuolization, which are thought to increase in abundance as the liver is assaulted by pollutants. The gonadosomatic index, a measure of the relative size of the testis also did not vary between treatments or between treatments and control in either experiment. The lack of alteration in gonadosomatic indices among treatments and experiments is paralleled by a lack of changes in spermatogenic cell abundance, suggesting that spermatogenesis was not affected by any of the E2 exposures. These findings suggest that the occurrence of intersex, a hallmark of EAC exposure in wild fish, may require a longer exposure period that accomplished in this study.

The behavioral challenge assay produced statistically significant, but conflicting results when experiment one and two are compared. The objective of the assay is to assess the ability of exposed male fathead minnows to establish and defend a nest site in direct competition with a control male fathead minnow. The assumption underlying this assay is that the androgen-driven nest defense may be muted in fish exposed to estrogens which may depress androgen expression (Trudeau et al., 1993). In experiment one, control males out-competed ST treatment males at a $3: 1$ ratio ( $p<0.001$, Fisher's Exact test). However, the same treatment in experiment 2 resulted in ST males out-competing control males at a $2: 1$ ratio $(p<0.001)$. Also in experiment two, but not experiment one, control males out-competed $\mathrm{HI}$ males at a rate of 3:1 $(p<0.001)$. For all other treatments in both experiments, ETOH solvent control fish either competed similarly or slightly out-competed treatment males. Contradictory results in behavioral assays have been reported in previous studies using this, or similar competitive challenge assays (Martinovic et al., 2007; Schoenfuss et al., 2008; Barber et al., 2007) and may reflect the complexity of internal and exogenous stimuli that precede reproductive behaviors.

The results of this study indicate the danger of Type I (false positive) and Type II (false negative) errors toxicological studies by not taking into account the timing of exposure to EACs. For example, an assessment of acute exposure to estrogenic EACs in male wild-caught fish may result in a Type I error if plasma vitellogenin concentrations were found to be high even if the source of the exogenous estrogen may have been transient. Lagoon-type wastewater treatment often results in semi-annual discharge of treated effluent that may increase estrogenicity in a river stretch for several days and, based on the results of this study (Table 2), may result in elevated plasma vitellogenin concentrations in male fish weeks after the discharge has ceased.

The results of this study also indicate that the selection of a fish species may have ramifications for the interpretation of results especially in field studies (Table 2). A fish species that inhabits a larger geographic area (for example many piscivore fishes) or engages in seasonal migrations may exhibit high plasma vitellogenin concentrations without vitellogenin mRNA expression if caught a distance from the exposure site or may exhibit only vitellogenin mRNA expression without measurable plasma vitellogenin if exposure was transient during migration or predatory searches. The use of caged fishes (for example Hemming et al., 2001, 2004; Kolok et al., 2007) could alleviate some of the uncertainty associated with the exposure history of individual wild-caught fish and may provide a reference sample for such field studies.

Factors such as the length of exposure (stationary vs. migratory species), knowledge of the organisms exposure history (laboratory vs. field studies) and control of exposure concentrations (individual compounds vs. temporally complex effluents) need to be considered in the development of experimental designs when assessing putative in situ estrogenic exposures. This study highlights the complexity of organismal responses to endocrine active compounds by active vertebrates and emphasizes the need to consider a multitude of biological endpoints when designing exposure studies.

\section{Acknowledgments}

We thank Gerald LeBlanc at North Carolina State University for the generous donation of the fathead minnow vitellogenin antibody used in this study. This research was supported by the US EPA STAR Program (Grant \# R832741-01-1) and a St. Cloud State University student research grant to $\mathrm{KMH}$. Assistance in the laboratory was provided by Tim Loes, Meghan McGee Painter, Kirstin Pfannenstein, Meghan Buerkley, John Roos and Amanda Brown. Three anonymous peer reviewers improved the manuscript through their thoughtful comments. The United States Environmental Protection Agency through its Office of Research and Development partially funded and collaborated on the research described here. It has been subjected to Agency review and approved for publication.

\section{References}

Barber, L.B., Lee, K.E., Swackhamer, D.L., Schoenfuss, H.L., 2007. Reproductive responses of male fathead minnows exposed to wastewater treatment plant effluent, effluent treated with XAD8 resin, and an environmentally relevant mixture of alkylphenol compounds. Aquat. Toxicol. 82, 36-46.

Bayley, M., Nielsen, J.R., Baatrup, E., 1999. Guppy sexual behavior as an effect biomarker of estrogen mimics. Ecotoxicol. Environ. Safety 43, 68-73.

Biales, A.D., Bencic, D.C., Lazorchak, J.L., Lattier, D.L., 2007. A quantitative real-time polymerase chain reaction method for the analysis of vitellogenin transcripts in model and nonmodel fish species. Environ. Toxicol. Chem. 26, 26792686.

Bistodeau, T.J., Barber, L.B., Bartell, S.E., Cediel, R.A., Grove, K.J., Klaustermeier, J., Woodard, J.C., Lee, K.E., Schoenfuss, H.L., 2006. Larval exposure to environmentally relevant mixtures of alkylphenolethoxylates reduces reproductive competence in male fathead minnows. Aquat. Toxicol. 79, 268-277.

Bjerselius, R., Lundstedt-Enkel, K., Olsen, H., Mayer, I., Dimberg, K., 2001. Male goldfish reproductive behavior and physiology are severely affected by exogenous exposure to $17 \beta$-estradiol. Aquat. Toxicol. 53, 139-152.

Carson, F.L., 1997. Histotechnology, 2nd ed. American Society for Clinical Pathologists Press, Chicago.

Denny, J.S., 1987. Guidelines for the culture of fathead minnows Pimephales promelas for the use in toxicity tests, EPA/600/3-87/001.

Diamond, J., Bowersox, M., Latier, H., Barbour, C., Bearr, J., Butcher, J., 2005. Effects of pulsed contaminant exposure on early life stages of the fathead minnow. Arch. Environ. Contam. Toxicol. 49, 511-519.

Gabe, M. 1976. Histological Techniques. Springer-Verlag, New York.

Gordon, D.A., Tooth, G.P., Graham, D.W., Lazorchak, J.M., Reddy, T.V., Knapp, C.W., deNoyelles Jr., F., Campbell, S., Lattier, D.L., 2006. Effects of eutrophication on vitellogenin gene expression in male fathead minnows (Pimephales prome- 
las) exposed to $17 \alpha$-ethynylestradiol in field mesocosms. Aquat. Toxicol. 142, 559-566.

Handy, R.D., 1994. Intermittent exposure to aquatic pollutants: assessment, toxicity and sublethal responses in fish and invertebrates. Comp. Biochem. Physiol. 107, 171-184.

Harries, J.E., Sheahan, D.A., Jobling, S., Matthiessen, P., Neall, P., Sumpter, J.P., Tylor, T., Zaman, N., 1997. Estrogenic activity in five United Kingdom rivers detected by measurements of vitellogenesis in caged male trout. Environ. Toxicol. Chem. $16,534-542$.

Hemmer, M.J., Bowman, C.J., Hemmer, B.L., Friedman, S.D., Marcovich, D., Kroll, K.J., Denslow, N.D., 2002. Vitellogenin mRNA regulation and plasma clearance in male sheepshead minnows, (Cyprinodon variegatus) after cessation of exposure to $17 \beta$-estradiol and $p$-nonylphenol. Aquat. Toxicol. 58, 99-112.

Hemming, J.M., Allen, H.J., Thuesen, K.A., Turner, P.K., Waller, W.T., Lazorchak, J.M., Lattier, D., Chow, M., Denslow, N., Venables, B., 2004. Temporal and spatial variability in the estrogenicity of a municipal wastewater effluent. Ecotoxicol. Environ. Safety 57, 303-310.

Hemming, J.M., Waller, W.T., Chow, M.C., Denslow, N.D., Venables, B., 2001. Assessment of the estrogenicity and toxicity of a domestic wastewater effluent flowing through a constructed wetland system using biomarkers in the male fathead minnow (Pimephales promelas Rafinesque 1820). Environ. Toxicol. Chem. 20, 2268-2275.

Jobling, S., Nolan, M., Tyler, C.R., Brighty, G., Sumpter, J.P., 1998. Widespread sexual disruption in wild fish. Environ. Sci. Technol. 32, 2498-2506.

Jobling, S., Coey, S., Whitmore, J.G., Kime, D.E., Van Look, J.K.W., McAllister, B.G., Beresford, N., Henshaw, A.C., Brightly, G., Tyler, C.R., Sumpter, J.P., 2002. Wild intersex roach (Rutilus rutilus) have reduced fertility. Biol. Reprod. 67, 515-524.

Kolok, A.S., Snow, D.D., Kohno, S., Sellin, M.S., Guillette Jr., L.J., 2007. Occurrence and biological effects of exogenous steroids in the Elkhorn River, Nebraska, USA. Sci. Tot. Environ. 388, 104-115.

Korte, J.J., Kahl, M.D., Jensen, K.M., Pasha, M.S., Parks, L.G., LeBlanc, G.A., Ankley, G.T., 2000. Fathead minnow vitellogenin: complementary DNA sequence and messenger RNA and protein expression after $17 \beta$-estradiol treatment. Environ. Toxicol. Chem. 19, 972-981.

Liao, T., Guo, Q.L., Jin, S.W., Cheng, W., Xu, Y., 2008. Comparative responses in rare minnow exposed to $17 \beta$-estradiol during different life stages. Fish Physiol. Biochem. 35, 341-349.

Martinovic, D., Hogarth, W.T., Jones, R.E., Sorensen, P.W., 2007. Environmental estrogens suppress hormones, behavior, and reproductive fitness in male fathead minnows. Environ. Toxicol. Chem. 26, 271-278.

Martinovic, D., Denny, J.S., Schmieder, P.K., Ankley, G.T., Sorensen, P.W., 2008. Temporal variation in the estrogenicity of a sewage treatment plant effluent and its biological significance. Environ. Sci. Technol. 42, 3421-3427.
Panter, G.H., Thompson, R.S., Sumpter, J.P., 2000. Intermittent exposure of fish to estradiol. Environ. Sci. Technol. 34, 2756-2760.

Pfaffl, M.W., Horgan, G.W., Dempfle, L., 2002. Relative expression software tool (RESTC) for group-wise comparison and statistical analysis of relative expression results in real-time PCR. Nucl. Acids Res. 2002;30:e36, doi:10.1093/nar/30.9.e36 (http://nar.oxfordjournals.org/content/ vol30/issue9/).

Purdom, C.E., Hardiman, P.A., Bye, V.J., Eno, N.C., Tyler, C.R., Sumpter, J.P., 1994. Estrogenic effects of effluents from sewage treatment works. Chem. Ecol. 8, 275-285.

Rogers-Grey, T.P., Jobling, S., Morris, S., Kelly, C., Kirby, S., Janbakhsh, A., Harries, J.E. Waldock, M.J., Sumpter, J.P., Tyler, C.R., 2000. Long-term temporal changes in the estrogenic composition of treated sewage effluent and its biological effects on fish. Environ. Sci. Technol. 34, 1521-1528.

Schmid, T., Gonzalez-Valero, J., Rufli, H., Dietrich, D.R., 2002. Determination of vitellogenin kinetics in male fathead minnows (Pimephales promelas). Toxicol. Lett. $131,65-74$.

Schoenfuss, H.L., Bartell, S.E., Bistodeau, T.B., Cediel, R.A., Grove, K.J., Zintek, L., Lee, K.E., Barber, L.B., 2008. Impairment of the reproductive potential of male fathead minnows by environmentally relevant exposures to 4-nonylphenol. Aquat. Toxicol. 86, 91-98.

Schoenfuss, H.L., Levitt, J.T., Van Der Kraak, G., Sorensen, P.W., 2002. Ten week exposure to treated sewage effluent discharge has relatively minor, variable effects on reproductive behavior and sperm production in goldfish. Environ. Toxicol. Chem. 21, 2185-2190.

Smith, R.J.F., 1978. Seasonal changes in the histology of the gonads and dorsal skin of the fathead minnow, Pimephales promelas. Can. J. Zool. 56, 2103-2109.

Ternes, T.A., Stumpf, M., Mueller, J., Haberer, K., Nilken, R.D., Servos, M., 1999. Behavior and occurrence of estrogens in municipal sewage treatment plantsI. Investigations in Germany, Canada and Brazil. Sci. Total Environ. 225, 81-90.

Thorpe, K.L., Benstead, R., Hutchinson, T.H., Tyler, C.R., 2007. Associations between altered vitellogenin concentrations and adverse health effects in fathead minnow (Pimephales promelas). Aquat. Toxicol. 85, 176-183.

Trudeau, V.L., Wade, M.G., Van der Kraak, G., Peter, R.E., 1993. Effects of $17 \beta$-estradiol on pituitary and testicular function in male goldfish. Can. J. Zool. 71, 11311135.

Unger, L.M., 1983. Nest defense by deceit in the fathead minnow, Pimephales promelas. Behav. Ecol. Sociobiol. 13, 125-130.

Vajda, A.M., Barber, L.B., Gray, J.L., Lopez, E.M., Woodling, J.D., Norris, D.O., 2008 Reproductive disruption in fish downstream from an estrogenic wastewater effluent. Environ. Sci. Technol. 42, 3407-3414. 